\title{
Implementing CRM System in a Global Organization National vs. Organizational Culture
}

\author{
Linda Frygell \\ Department of Management and \\ Engineering \\ Linköping University, Sweden \\ Linda Frygell@Liu.se
}

\author{
Jonas Hedman \\ Department of IT Managment \\ Copenhagen Business School, \\ Denmark \\ jh.itm@cbs.dk
}

\author{
Sven Carlsson \\ Department of Informatics \\ Lund University, Sweden \\ Sven.Carlsson@ics.lu.se
}

\begin{abstract}
This paper presents a longitudinal case study of a multi-national company's Customer Relationship Management implementation in China, Poland, Russia, Middle East, Dubai, Pakistan, Iran, Korea and Japan. Although the cooperation has extensive experience in implementing systems in its different global subsidiaries, and has planned the implementation well, the implementation was not a complete success. The study has identified that the cultural factor are important, but not stressed enough in the current CRM literature. Understanding the difference between the organizational culture in which the system is developed and the national culture in which the system is implemented, as well as having a strategy for how to embrace and control/adjust to cultural values, is vital for a successful system implementation.
\end{abstract}

\section{Introduction}

Organisations around the world are increasing their customer relationship management, CRM systems efforts. It is viewed as a strategic decision [8]. The goal with CRM systems is to find the 'best' customers, strengthen the relationship to the customer, and thereby maximize the value for the customers [8, 18, 32]. CRM systems support customer touch points through integration of the back-office and front-office functions, and they provide support for two capabilities [6]. The first is related to data processing, which can potentially result in a number of positive effects, including improved customer service, opportunities for crossselling and up-selling, information regarding customers' habits and preferences, an integrated and complete view of customers, and efficient service centres. The other capability is related to technology and its uses. For instance, CRM systems can be employed in customer self-service, attracting existing and new customers through personalised communications, and integrating customer and supplier relationship construct metrics $[6,19]$.

The implementation of CRM systems poses clear risks, but it can also yield high rewards [32]. For instance there is evidence for well-managed CRM projects and business performance [8]. However, CRM systems implementation is challenging. In general, the failure rates for CRM projects are high, and recent research indicates a failure rate of between $30-70 \%[20,5]$.

Current research on CRM systems has addressed various factors that affect use and success [29, 10], management capability [8], implementation [13], and benefits [32]. The literature assumes a generic standardized process of managing customers. However, business practise and customer management varies between industries and countries.

The aim of this study is to provide insight into the role of culture in the development and implementation of CRM systems. The paper presents a longitudinal case study of a CRM development in a multi-national cooperation, $\mathrm{MNC}$ and its subsequent global CRM-system implementation. One of the main reasons for examining organizational culture in this particular study was to see if a strong organizational culture existed throughout the whole organization. We also wanted to understand if there were any differences in how the employees that developed and implemented the CRM perceived the organizational culture, compared to how the sales company where the CRM was being implemented viewed their organizational culture, since this perception can affect the process of implementation.

The paper is organised in the following structure: The next section presents a brief literature review, and is followed by the research approach. In the fourth section we present the development and implementation of the CRM system. The findings, as well as a discussion of the results in light of the role 
of culture in the development and implementation of CRM then follow this. We then conclude the paper.

\section{CRM Implementation Literature}

There are a few different approaches for implementing complex and large systems: piecemeal, big bang, and rollout. In the piecemeal approach, the modules are implemented continuously; in the big bang approach, all modules are implemented at the same time across the whole organisation; and in a rollout modules, as a framework, are developed at a primary site and then introduced to subsequent sites $[1,33]$. It has been believed that organizations that deploy CRM with a wider scope enjoy full benefits over a longer period of time and realize larger profits [19]. Regardless of which implementation approach is chosen, a number of factors are critical for successful implementation $[11,12]$. The concept of critical success factors, CSF is well established within the field of IS. In relation to CRM, there are studies addressing CSFs specifically, including: creating a vision and communicating it, readiness and ability to change, altering business processes prior to implementation, communicating management intention, effective top management support, having a balanced implementation team, training, and commitment to change [5]. Similar CSFs were found in a study of 57 organisations that had implemented CRM systems. Top management support and technological readiness were identified as the two implementation factors most critical for effectively implementing CRM systems correlating to success [10]. While other studies identified process fit, customer data quality, and system support as the main factors contributing to perceived success [29]. However, in CRM projects the criticality of the CSFs is highly dependent on the context. It is therefore important that organizations always consider the three components: human factor, process and technology since they constitute a balanced, systemic and integrated approach. CSFs are to be seen as tools that allow to evaluate the presence or not of factors that guarantee the success of a CRM strategy and implementation. [15, 25, 34] Although it is not enough to merely identify risk factors when commencing a CRM project since CSF does not have equal weightings [27]. It is for instance important to consider the complexity of the system, especially if the organisation is implementing using a phased rollout with increasing functionality as the organisation is maturing and adopting CRM. Often for benefits from a CRM to be realised it will have to undergo continuous redesigns [21]. It is not only the
CRM technology but also the customer-centric organizational system and general customer orientation within the organization that affect a firms overall CRM capability and business performance. This means that the organizational cultural context is important [17] for and has an impact on how successful the CRM implementation will be.

\subsection{Literature Review}

National and organizational culture research have emerged as two separate research streams with little overlap even though they both focus on defining the value of what distinguish one group from another group. Culture is a critical variable in explaining how social groups and individuals interact with IT [23]. It is very difficult to capture the cultural features of a particular organization, how it changes and what makes it change. There are a number of different perspectives on culture from a narrower management centric approach to a wider anthropological approach. Culture provides us with directions but also prevents us from seeing. Organizational culture is not only positive in the way it fulfills people's needs for meaning and guidance but also leads to restrictions of consciousness and closure of mind. Culture is not only a provider of clues for understanding social integration and guiding behavior but also a tool for developing sensitivity towards conflict and differentiation [3].

IS usually has an impact on the organizational structures and behavior by facilitating interorganizational communication and cooperation, improve work processes, make decision making more effective and intensify the controls of the organizations [31].

All technologies are knowledge based and part of the knowledge required to use a technology is built in by its creator and part of the knowledge comes from the mind of the user. This means that a group's cultural norms and values can condition the IS usage without any added social or technical constraints built in. Although the inter-group dynamics between the IS group and the users affect user assessments that new IS supports the work process correctly. Perception and responsiveness increase user acceptance of IS through social identification with the IS group and also makes user more tolerable to problems with the new IS [16]. The major feature distinguishing IS from other technology is its adaptability, that the same system can be implemented in different forms and functions in different organizations depending on the culture [9]. IS's adaptation to the existing culture increases the possibility that it will be implemented without problems and used $[3,9,28]$. The higher the 
degree of conflict between IS and the organizational culture the likelier the implementation is to fail [9].

Prior to introduction of a CRM the organization should define processes and structures in order to implement CRM successfully. When cogitating organizational redesign the company also needs to consider the structural issues. A centralized organization needs to establish an authority for defining cross-functional standards while a decentralized organization leaves the implementation lead to country organizations, which prevents conflicts with the existing culture [2]. In localized company mistakes will probably occur but it is companies that learn from blunders and foster an atmosphere where action, mistakes and learning are allowed that will be able to meet new challenges in the future [14].

CRM is most successfully implemented in an integrated organizational culture with cooperative, collaborative and trust based interaction where employees are empowered [14, 26], open to changes, have a positive attitude towards IS and where knowledge sharing is common practice. This since one of the fundaments for CRM is sharing of highquality customer information. If no sharing of information and knowledge is available within the company it is hard to maintain a rich customer knowledge base $[16,26]$.

\section{Research Approach}

This is a longitudinal single case study of a CRM implementation in a MNC. The study is conducted in two parts. The first part was an evaluation study during the fall of 2004 and the second part is based on project documentation and participatory observation from January 2005 to march 2008. The focus was on the CRM implementation process and the CRM in use. The research question centred on implementation success and failure factors. The literature on implementation CSFs, and especially CSFs for CRM implementation, was used to guide the study. Although the study is primarily inductive, empirically grounded, we recognize that the empirical findings are partly gathered, presented, and coloured by current research on CSFs for CRM systems implementation.

\subsection{Data Collection}

The data sources consist of interviews, internal documents, and participative observations in the implementation project. The main data sources were interviews and office visit observation. The first interviews were conducted with the global project manager, local project manager, and other managers in order to discover critical decisions and actions. The following interviews with end users were chosen to explore the consequences of decisions and actions on management level. In total, 25 interviews with 24 employees were conducted. All the interviews were individual interviews and were recorded and transcribed. Documents and internal reports were initially used to gain an overall picture of previous actions and events. The documentation, approx. 800 pages is in the form of reports, PowerPoint presentations, memos, personal notes, intranet web pages and files, educational web survey, guidelines, Business Process charts, and CRM training material. The purpose of the observations was to glean additional information that proved difficult to obtain through interviews. Events observed include project manager workshop; super user training for Nordic Countries and the US; follow-up training in Beijing; a telephone meeting with the CRM project manager for China; office visits in Sweden, China, Poland, Russia, Middle East, Korea and Japan

After the interviews were completed, a general analysis, themes, and coding were performed. First, the interviews were organized according to interviewees' roles in the project. For instance, the local project managers' answers were assessed in relation to one another in order to detect variances in their answers. Next, all the questions that were asked of all people were analysed. This involved grouping the questions into categories of positive vs. negative and good vs. bad responses. Further, all questions were separated into different themes, which corresponded to the factors identified by the research literature as critical for system implementations. The material was analysed several times in an attempt to identify patterns in the material as a whole, and also in the material grouped by factors like project roles, gender, previous IS implementation experience, culture and others that may have affected the implementation process.

\subsection{Data Analysis}

The collected data was analysed continuously to enrich the interviews that followed. The very first interview was an unstructured interview with the global Project Manager for the CRM implementation project. The interviewee was asked about the events of the first implementation, as well as his reflections on the matter. This interview led to the formation of a guideline for interviews with the Sales Company IS co-ordinators, and their input then further influenced the interview guides for local Project Managers. In turn, the interview guide for the CRM team members 
and the regular users was shaped in response to the answers provided by Sales Company IS coordinators.

\section{The MNC and its CRM System}

Prior to 2001, the organization's corporate support staff and its market and sales companies used different types of CRM systems. However, in 2001 the IT Board in the organization decided to standardise its CRM platforms globally. It was decided in 2002 that the organization would use inhouse developed systems from the USA and the Nordic countries as the platform for building a new global CRM system. In May 2002, the system was installed in the Nordic Sales Company.

During the pilot study in the Nordic Sales Company, it became clear that it was very difficult to make exact calculations of the benefits of using a CRM system, due to the intangible nature of benefits. Topics identified as benefits by the sales people and managers during interviews after implementation included: Increased efficiency in the day-to-day sales management activities; market and sales planning at higher organizational levels were viewed as easier to complete and took less time to perform; the availability of knowledge capture/organisational memory in the system was seen as a positive outcome; and Forecasts were easier to do compared to the situation before the systems was implemented.

In March 2003, the Nordic Pilot case was finalised. The main conclusion of the case was that the pilot project clearly demonstrated that the system could add significant value to organization's business. Later in April-May, preparation for the continued development, CRM phase 2 and a global roll-out, CRM phase 3 was undertaken, and in June 2003, the IT Board was presented with the proposal for the continuation of the implementation.

During the development in phase 2 and also in the continuing maintenance and development of the CRM system, the organization worked in close cooperation with an external software vendor. In the beginning of the CRM implementation the vendor was located in a Nordic country, but in $2005-2006$ the organization decided to change to an Indian software vendor due to a central strategic IToutsourcing decision.

The implementation approach chosen was a rollout approach in four waves; each wave was treated as an individual project and included approximately 400 end users and would cover 38 sales companies in 52 countries. The original time frame for phase 3 , wave 1 was specified to start on July 1, 2003, and be completed by April 31, 2004. A few modifications to the original rollout plan were done due to unforeseen circumstance and more prioritized local business projects between the waves.

Within each wave, a specific sub-project was to be set up for each sales company. The project team was to be staffed with people from the local organisation with a local project manager. For each sub-project there was also a dedicated CRM team, with a project coordinator from the Sales Tools Group, STG, Corporate IT supporting the local project. The local project leader was supposed to report to the steering committee for the local subproject. The central project manager for the implementation wave in question then reported to the Central Steering Committee in order to give a consolidated project overview about each wave's local sub-projects.

\subsection{Implementation in Different Countries}

The implementation in each country or region was managed according to an established organizational project management methodology. Within the project framework five main activities where performed and they were, see table 1:

Table 1. CRM project main activities

\begin{tabular}{|l|l|}
\hline No & Main activity \\
\hline 1 & $\begin{array}{l}\text { Central project manager workshop for all local } \\
\text { project managers at the company headquarter }\end{array}$ \\
\hline 2 & Local kick-off in the sales company. \\
\hline 3 & $\begin{array}{l}\text { To-be workshop to discuss the "as is" and "to be" } \\
\text { business processes and GAP analysis }\end{array}$ \\
\hline 4 & $\begin{array}{l}\text { Acceptance test, testing the system functionality } \\
\text { and the quality of the customer data. }\end{array}$ \\
\hline 5 & $\begin{array}{l}\text { Go-live workshop, including end user training } \\
\text { and super-user training and follow-up training. }\end{array}$ \\
\hline
\end{tabular}

Apart from the workshops other main project tasks were for instance: To write and establish the local project specification, continuously communicate project activities, administrate local IT investments and setting up for instance local servers needed for the CRM system, cleaning and enriching company data, write local CRM guidelines and create local templates, e.g. quotation templates in the system and establish local support and maintenance organization.

The country or regional sales offices varied significantly in size, number of employees and number of local offices within the country or region. The CRM implementation project was not to be labelled as an IT project but should be viewed as a business project, hence the recommendation from the central STG for the selection of the local CRM 
project manager to be a person from the business and not an "IT person". Before the central project workshop each local project manager was asked to prepare information about the sales company in general and also present a local IS status update at the workshop. It was more challenging for a newly employed person, like the Japanese CRM project manager, to gather the necessary business and IT information and drive change compared to project managers that were familiar with the business processes, respected in the organisation and had a well-established internal network. The only project manager that did not manage to finalising the project was the Japanese project manager who was replaced in the middle of the project. For more information regarding the local CRM project managers' experience see table 2 below.

Table 2. Summary CRM project manager experience

\begin{tabular}{|l|l|l|l|}
\hline Country/Region & Position & Years at the company & Previous IT project experience \\
\hline China & Business Area Sales Manager & $>10$ years & - No \\
\hline Poland & Project and Quality Manager & $>10$ years & - No \\
\hline Middle East region & $\begin{array}{l}\text { Managing Director in one of the } \\
\text { countries in the region }\end{array}$ & $>20$ years & $\begin{array}{l}- \text { Yes, CRM project manager in a } \\
\text { previous implementation wave }\end{array}$ \\
\hline Russia & Service Manager & $>10$ years & - No \\
\hline Ukraine & Financial and IT Manager & $>10$ years & $\begin{array}{l}\text { - Yes } \\
\text { - Running local IT projects }\end{array}$ \\
\hline Korea & Business Area Sales Manager & $>20$ years & - No \\
\hline Japan & Business Area Sales Manager & $<1$ year & - No \\
\hline
\end{tabular}

After the central workshop the next milestone for the local project manager was to produce a project specification and get it approved by the local steering committee. The project team outlined several risks, including time conflict between data cleaning and sales, lack of commitment from segment managers, resistance to changing sales behaviour, not sufficient IT network, network not fast enough and lack of resources to the local CRM project.

Before the kick-off all the local sales people in each country should have received communication about the CRM projects purpose, benefits and time schedule. In China a memo was sent to all employees, which explained why a CRM was essential to the Chinese sales company. During the kick-off, the Managing Director and three local project owners gave presentations and stressed the importance of the CRM project. An introduction of the CRM project was given, as well as a discussion about how to implement the project. In Poland the kick-off was held as two separate meeting at the two offices where the majority of the employees were located. The Managing Director, MD did not attend but segment managers participated in the kick-off. In Ukraine all employees where informed about the CRM project at the kick-off and it was more of an informal discussion session. In the Middle East the kick off was done in the Middle East region's main office, Dubai. Information and previous experiences both in regards to the CRM project process and the CRM had been communicated in advance by the local CRM project manager, who was also part of the local top management team as an MD for one of the countries in the Middle East region. In both Japan and Korea a memo was sent out to all employees in advance. In Japan, Tokyo office, almost all sale employees had been gathered but when asked people said that this was the first time they heard anything about a CRM project. The kick off was more of an information activity and there were no questions or discussions during the presentation. In Korea the kick off was more focused on the top management team and the local CRM team and questions and concerns where discussed in smaller groups.

China was the only country that invited a Change Management expert to hold change management training for the CRM team as part of the kick-off agenda. This was done to raise the awareness of the need for change management and also give some practical examples on how to work with change.

As communication is an important part of change management a communication plan was established for each local project. In the countries where they had a Communication Manager, this person was appointed as the communication expert in the project team and responsible for executing the communication plan. The overall objective of the communication plan was to ensure that all the targeted groups of people received the information they needed in order to successfully play their roles in the project.

The support from top management was good in the majority of the countries. In China the top management thought that they had been very clear about the importance of the system. However, remarks like this were not uncommon: "[...] Management they say enough but do not do enough. They need to think how to push the people, how especially the middle management, not all of them have fully accepted CRM system and the CRM team 
or maintenance team do not have the authority to tell other people what to do."

In China there existed no previous documentation of Business Processes, BP. The local CRM implementation team was responsible for documenting the business processes, which were to be agreements on how to conduct business. The local CRM team was also in charge of conducting the GAP analysis to see if any misfits existed between the BP and the CRM system. They were to develop guidelines based on this analysis. In China, the local CRM team mapped the segments' different BP as either "as is" or "to be", but no real GAP analysis was performed. In the second, third and fourth wave of CRM implementation all countries were expected to map their "as is" and "to be" BP. But already in the second wave there were complaints from countries, since they did not understand the reason for mapping "as is" BP since the BP in the CRM system "to be" was already set, i.e. the system would not change even if GAPs were found. Acceptance tests included everything from functionality to customer and contact data. The acceptance test followed a test protocol and dealt with: tasks, company data, guidelines and templates, response time, and connection to the ERP system in question.

The customer data cleaning was predicted to take a lot of time and effort based on previous experience from the Nordic Pilot. The CRM system's customer data was collected from a variety of sources, including other systems and business cards. The business cards were scanned after being collected from sales people. In the data cleaning process there was also an external company involved that had been assessed and approved by the central STG before the CRM implementation started. This external partner was a North American company specializing in customer and credit data information. According to the sales companies this external North American customer information provider did not have good or correct local customer information for mid-size and smaller local companies in China, Poland, Russia, Ukraine, Korea and Japan. The CRM team in Japan were extremely concerned with the customer data quality since it also affected the ERP integration, the integration was set up based on unique customer numbers that they forced additional data cleaning and postponed the go-live date.

The project coordinator from the Sales Tools Group was together with the local project manager responsible for completing the super user training and acceptance tests. These were to be performed before end user training to ensure that the BP and the system were aligned, that the guidelines were suitable, and that bugs were reported or fixed.
In China the planned launch date was postponed and a new date was set to May 1, 2004, but this was later revised as well. The delay of the launch date was due to functionality enhancement requests regarding the openness of the system, security issues, and the new launch date for CRM was set to September 2004. One concern was that employees could steal customer information upon leaving the company. The issue that delayed the launch of the system in China was the so-called security issue. The management in China found that the openness of the CRM was a real problem and explain why they did not foresee it from the beginning of the implementation: "another problem and that is the security [...] we believe that IT should have a policy and safe guard the security, we do not think about it and do not consider it, we heard that it is a open system but do not realise that it is a risk and so easy to get all the information." There were differing views on the issue, but a major concern was that employees might leave the company and take critical information with them, perhaps to a competitor. When asked about the security issue, the respondents did not find it to be a specific Chinese issue: "Unfortunately it has been labelled as a Chinese security issue [...] that is just because we are the first country to come about it [...] Not a china issue, are main competitors has come in the Nordic countries [...] World wide problem that we need to take very seriously." One reason for this: "Some people have not seen the system and do not know what a powerful tool it can be." Two of the countries in the first wave of implementation were not concerned about the openness of the system, and one local project manager replied: "like visible information, [...] too many restrictions for users and what they can do at the moment. [...] is working a lot with external sales people and they can not use the CRM system, it must be open to them in the future. " Functionality changes were made in the CRM in order to restrict access to information, and it was decided that users should only be able to see information related to their segment of work. Limitations to replication of databases, exporting information, and printing reports were also made.

The main CRM training for end-users was held by a central educator and was divided into two half-day sessions per person. The training was initially performed in English, with a local interpreter available to translate when necessary. In all countries except the Middle East the preferred language was the local language. During the training sessions, emphasis was placed on having a CRM system, which meant a "sell in" opportunity to the users that were not already in favour of using the CRM system. 
Local personnel in the user's native language gave follow-up training. This training, was more a handson practice to refresh everyone's memory, and lasted half a day. During the session, the users discussed issues and concerns related to $\mathrm{BP}$ and how to complete tasks in the system.

After the restricted access functionality was added to the CRM the security issue was discussed centrally and with the countries that were going to implement the CRM in the second wave in an ad hoc manner, i.e. leaving it up to the global and local CRM project manager to discuss and report back to the central Sales Tools team. The Global Reference Group recommended an open system and concluded that most information is not very sensitive from a competitive perspective. The proposal of an open system was also supported by the Central IT Steering Committee. Security restrictions in previous CRM systems in the organization had always been removed after some time of usage. It was also well known and well established in the central organisation that transparency and sharing of information is an important foundation for a successful CRM.

After the second wave was finalized and the projects closed the Central IT steering committee wanted to improve communication in regards to the CRM since a closed and restricted system due to security issues would affect the expected benefits of using a CRM system. Two activities not included in the original overall project specification were added, and they were: Interview with different end users including Managing Directors, MD in sales companies using the CRM and a project called "Securing wave 1 and 2".

One MD from the second wave said when he was interviewed: "Limited access to the report. We discussed it. Compare it to access to our office, one key. It is not so difficult to break in. Everybody can access the office. You can never secure one hundred percent."

In the securing of the wave 1 and 2 the major outstanding issues from project completion reports, wave 1 and 2 were assessed and addressed based on urgency, impact and priority.

On of the main issues found was the poor utilization of the CRM system. The CRM usage was supposed to be analysed and connected to Key Performance Indicators, KPI to better align with business performance goals and measurement in general. The assumption was that the connection between CRM usage and the KPI would ensure management involvement and act as an incentive for the sales force to use the system. More CRM project communication from the central STG group was requested. Sales people in the organisation wanted to know what was happening in the different implementation waves and receive information on CRM development, bug-fixes and errors. A CRM system newsletter was established and included for instance system development information, success stories, tips and tricks and usage statistics. Webinars, user training on-line and also, where needed, additional end user training was performed.

One of the effects from the securing of wave 1 and 2 was that the CRM project in the third and the fourth wave of implementation included a mandatory formalized security discussion where the local management team was asked to fill in a Microsoft Excel sheet containing a set of functionality and security dimensions. After the security sheet was filled in the central CRM project manager and the local management team where to have a security discussion. After the security discussion the Managing Director in each country or sales company region had to sign a security agreement clearly stating that he/she had understood the possible information security issue in the CRM systems and implications of allowing the system to either be totally open, partially restricted or closed based on business segment. In Poland, Russia, Ukraine and Korea it was after the security discussion decided to leave the CRM open. In the Middle East management decided to restrict the CRM by segment and in Japan management wanted to start with the system open and then re-assess the possible security issue after some time of usage.

Apart from adding local management expectation in order to be able to set CRM KPI and a formalized security discussion the four waves followed more or less the project management methodology and the main activities initialized in the first wave.

\section{Findings and Conclusion}

In this section we present the findings. and discuss what can be interpreted as a multidimensional cultural issue that emerged from the case. Furthermore, we discuss the cultural factor not receiving enough attention in the current CRM literature.

\subsection{Organisational Culture and National Culture}

A cyclical relationship exists between system implementations and organizational culture; CRM implementations can affect organizational culture, and organizational culture often affects system implementations. 
Prior to introducing the CRM the organization should define processes and structures depending on a centralized or de-centralized organizational structure in order to successfully implement CRM [2]. The organization did define sales company BP but did not fully address the possible structural issues in implementing a CRM in a matrix organization where you have local sales companies, subsidiaries with their internal hierarchical structure working for different divisions/segments with their hierarchies as well as having a centralized global IT department with their internal structure.

Researchers stresses the importance of having an organizational culture which is based on trust and collaboration where employees feel empowered in order to have a successful CRM implementation [14, 26]. Among sales people, we observed an unwillingness to share the customer information. This may be related to the importance of personal relationships in China [24], but it could also depend on the way sales people traditionally worked in China, Poland, Russia, Ukraine, Middle East, Korea and Japan i.e. before the CRM. After the CRM was introduced many sales persons did not feel empowered initially. Their perceived sales person value was for many connected to a sales person knowing and owning the customer information, and when the CRM was implemented they had been forced to give up their perceived value by handing over their customer information to be imported in the system during the data cleaning process.

That relationship building is important in the sales company is evident from discussions with the sales people but not possible to verify in the evaluation. One comment that could indicate that relationships are important from a sales person during training in Russia: “, [...] but where do I put information about this guys interest his birthday, what he likes, the name of his wife, the children?" Another thing that was mentioned in many training sessions in the different countries was the fact that the sales people felt controlled by management by this new CRM. If this perception of control is derived from the security discussions or based on the expectation from management to produce a certain number of documents in the system, KPI measurements is unclear but this control impression and hesitation in sharing customer information was not foreseen and brought up during the Nordic pilot project. It is likely that the Nordic or central STG cultural perspective acted as blinders and prevented them from seeing outside their own cultural restriction and hence could not see the complexity and the possible impact when national, organizational and professional cultures are colliding in a global MNC change project in the form of an CRM implementation.

In the Chinese context, supervisory commitment plays an important role in employees' jobsatisfaction, turnover intention, and job performance, as well as in their individual and organizational outcome [7]. This probably holds true in the sales company in China, and for hierarchical organizational cultures in general. In regards to the local project manager and his or her hierarchical organizational position we cannot draw any conclusion from this local project manager sample. However, it is likely that an experienced and locally well respected project manager influences the CRM project positively when it comes to willingness in the CRM team and sales people to commit to the change and project work in general. Some of the problems with implementing the CRM arose because the local organizational culture was not taken into account [20] and assessed properly before the implementation started. The way the USA and the Nordic sales company worked with their sales processes and customers, their BP were embedded in the new system from the beginning, since the platform for the new CRM was their old in-house CRM. In the pilot project, which influenced the development of the CRM, the most it was only the Nordic sales company that participated. The only other factor influencing the development phase was a usability study performed by an external usability expert in 2003 . This usability report was done with a focus on graphical cognitive usability styles in a Nordic setting. No usability study in regards to possible different cultural cognition aspects were performed. There was no mentioning of usability in relation to organizational BP requirements, possible technical network related issues or local regulations.

Collecting and reviewing existing customer data records are vital for CRM implementation, a sentiment that all respondents agreed with. The data cleaning process took more time and resources than anticipated in all countries. The customer data and credit provider was also selected without considering the data quality for medium-sized and small local business in different countries with language and alphabets different from the western characters. Even though the data cleaning process was rather thorough, some of the common problems [30], like missing customer data and out-of-date information about customers, were still a problem that affected the respondents' daily work even after the local CRM project was closed.

Since the CRM was an in-house developed system some users, for instance the Russian sales, had high expectations on how customized the CRM 
would be to their local needs. During training, many users found the system to be cumbersome to use and that it did not make them more efficient but actually had the opposite effect. Using the CRM took time away from sales and added to what was seen as additional administrative tasks added to their BP without any real rational reasons or benefits. In some countries the implementation of the CRM also changed the distribution of work in between administrative personnel, sales people and the management.

As mentioned earlier, the local organizational culture is affected by the larger national culture. Globalization culture, and IS has been [22] and IS field has primarily studied IS and culture from the perspective of culture as an independent variable explaining, for example, problems in IS implementation and use in different cultural contexts. In our case, the difference between the effects of Nordic and the different sales companies national culture in part explains some of the implementation problems. There is room to advance the IS field [22] and one interesting approach is to investigate cultural intelligence, CQ [4]. CQ measures an individual's ability to function and manage effectively in culturally diverse contexts and settings. CQ is a multidimensional construct and includes mental capabilities. From an IS-perspective, CQ is relevant because it focuses on how individuals and organizations can improve their CQ. Therefore, a way forward for individuals and organizations operating in culturally diverse contexts is to measure their CQ and determine how it can be improved.

\section{Table 3. Summary main findings}

\section{Customer knowledge and information}

- Sharing of customer information is not only about sharing data. Organisation, profession, country and culture affects how customer information is handled and valued.

\section{Change Management}

- It is essential to continuously work with change management throughout the IT project implantation.

- The local CRM project manager role was extremely important since he/she was the main change agent in the organisation that understood the local cultural context.

\section{Culture}

- Culture is a multi-dimensional phenomena and must be properly addressed in IT projects.

- Culture" is embedded by designers and developers in the actual IT artefact.

- Culture needs to be considered before, during and after implementation of an IT artefact in order for the project to be successful.

\subsection{Conclusion}

The reasons for CRM-failures are often the result of companies lacking a clear understanding of what the CSFs for CRM are. The organization's implementation of its CRM system largely followed the suggested CSFs found in the current CRM literature. Still, the implementation was not a complete success. The national culture in the MNC's headquarter where the main development of the CRM was performed is infused in the system, and basic design logics built into the system are partly in conflict with national culture in the countries where the system was being implemented. The CRM that was implemented in the organization in four waves from 2003 to the end of 2006 is, despite its initial resistance from end users and lacking functionality, still used in the case study organization today 2016.

Our study identified that the cultural factor is not identified and stressed enough in the current CRM literature. Based on the study, we tentatively suggest that a new CSF should be "taking care" of organizational and national culture. We propose that a way forward for IS research and practice is to address how individuals and organizations can improve their cultural intelligence.

\section{References}

[1] Al-Mudimigh, A., Zairi, M. and Al-Mashari, M. ERP software implementation: an integrative framework. European Journal of Information Systems 10, 4, 2001, 216226.

[2] Alt, R. and Pushmann, T. Successful practices in customer relationship management. Proceedings of the 37th Annual Hawaii International Conference, 2004, 9.

[3] Alvesson, M. Cultural perspectives on organizations. Cambridge University Press, New York, NY, USA, 1993.

[4] Ang, S., Van Dyne, L. and Koh, C. et al. Cultural Intelligence: Its Measurement and Effects on Cultural Judgment and Decision Making, Cultural Adaptation and Task Performance. Management and Organization Review 3, 3, 2007, 335-371.

[5] Brendler, W. 8 Critical factors that make or break CRM. Target Marketing 24, 4, 2001, 57-61.

[6] Chen, I. and Popovich, K. Understanding customer relationship management, CRM. Business Process Mgmt Journal 9, 5, 2003, 672-688.

[7] Cheng, B., Jiang, D. and Riley, J. Organizational commitment, supervisory commitment, and employee outcomes in the Chinese context: proximal hypothesis or global hypothesis?. Journal of Organizational Behavior 24, 3, 2003, 313-334. 
[8] Coltman, T. Why build a customer relationship management capability?. The Journal of Strategic Information Systems 16, 3, 2007, 301-320.

[9] Cooper, R. The inertial impact of culture on IT implementation. Information \& Management 27, 1, 1994, 17-31.

[10] Croteau, A. and Li, P. Critical Success Factors of CRM Technological Initiatives. Canadian Journal of Administrative Sciences / Revue Canadienne des Sciences de l'Administration 20, 1, 2009, 21-34.

[11] Delone, W. and McLean, E. The DeLone and McLean model of information systems success: a ten-year update. Journal of Management Information Systems 19, 4, 2003, 9-30.

[12] DeLone, W. and McLean, E. Information Systems Success: The Quest for the Dependent Variable. Information Systems Research 3, 1, 1992, 60-95.

[13] Finnegan, D. and Currie, W. A multi-layered approach to CRM implementation: An integration perspective. European Management Journal 28, 2, 2010, 153-167.

[14] Galbreath, J. and Rogers, T. Customer relationship leadership: a leadership and motivation model for the twenty- first century business. The TQM Magazine 11, 3, 1999, 161-171.

[15] Garrido-Moreno, A. and Padilla-Meléndez, A. Analyzing the impact of knowledge management on CRM success: The mediating effects of organizational factors. International Journal of Information Management 31, 5, 2011, 437-444.

[16] Gefen, D. and Ridings, C. IT acceptance. SIGMIS Database 34, 3, 2003, 25-40.

[17] Iriana, R., Buttle, F. and Ang, L. Does organisational culture influence CRM's financial outcomes?. Journal of Marketing Management 29, 3-4, 2013, 467-493.

[18] Jayaganesh, M., Shanks, G. and Carlsson, S. A framework for understanding Customer Relationship Management system benefits. ACIS 2004 Proc.,, 2004, 4.

[19] Kim, S. and Mukhopadhyay, T. Determining Optimal CRM Implementation Strategies. Information Systems Research 22, 3, 2011, 624-639.

[20] Krigsman, M. CRM failure rates. ZDNet, 2009. http://blogs Zdnet Comprojectfailures.

[21] Kumar, V., Sunder, S. and Ramaseshan, B. Analyzing the Diffusion of Global Customer Relationship Management: A Cross-Regional Modeling Framework. Journal of International Marketing 19, 1, 2011, 23-39.
[22] Leidner, D. Globalization, culture, and information: Towards global knowledge transparency. The Journal of Strategic Information Systems 19, 2, 2010, 69-77.

[23] Leidner, D. and Kayworth, T. Review: a review of culture in information systems research: toward a theory of information technology culture conflict. MIS Quarterly 30, 2, 2006, 357-399.

[24] Martinsons, M. and Westwood, R. Management information systems in the Chinese business culture: An explanatory theory. Information \& Management 32, 5, 1997, 215-228.

[25] Mendoza, L., Marius, A. and Pérez, M. Critical success factors for a customer relationship management strategy. Information and Software Technology 49, 8, 2007, 913-945.

[26] Ocker, R. and Mudami, S. Assessing the readiness of firms for CRM: a literature review and research model', in System Sciences. Proceedings of the 36th Annual Hawaii International Conference,, 2003, 10.

[27] Papadopoulos, T., Ojiako, U., Chipulu, M. and Lee, K. The criticality of risk factors in customer relationship management projects. Proj Mgmt Jrnl 43, 1, 2012, 65-76.

[28] Pedron, C., Picoto, W., Dhillon, G. and Caldeira, M. Value-focused objectives for CRM system adoption. Industr Mngmnt \& Data Systems 116, 3, 2016, 526-545.

[29] Roh, T., Ahn, C. and Han, I. The priority factor model for customer relationship management system success. Expert Systems with Applications 28, 4, 2005, 641-654.

[30] Ryals, L. and Payne, A. Customer relationship management in financial services: towards informationenabled relationship marketing. Journal of Strategic Marketing 9, 1, 2001, 3-27.

[31] Saarinen, T. An expanded instrument for evaluating information system success. Information \& Management $31,2,1996,103-118$

[32] Shanks, G., Jagielska, I. and Jayaganesh, M. A framework for understanding customer relationship management systems benefits. Commun. Assoc. Inf. Syst $25,1,2009,26$.

[33] Umble, E., Haft, R. and Umble, M. Enterprise resource planning: Implementation procedures and critical success factors. European Journal of Operational Research 146, 2, 2003, 241-257.

[34] Wang, Y. and Feng, H. Customer relationship management capabilities. Management Decision 50, 1, 2012, 115-129. 